\title{
Entartung: as vicissitudes de uma palavra tabu. Alguns aspectos do uso das palavras "Entartung" e "Degeneration" em Nietzsche*
}

\author{
Janske Hermens**
}

Resumo: Com frequência, acredita-se ser Nietzsche uma das fontes de inspiração do uso nazista da palavra 'Entartung', que é notória, entre outros, por causa do conceito nazista de 'Entartete Kunst'. Neste ensaio, defende-se que o uso nietzschiano da palavra era bastante diversificado e ambíguo, e inapropriado à utilização nazista. Antes de mais nada, Nietzsche não limita seu uso de 'degeneração' ao domínio fisiológico ou a grupos específicos de pessoas. Isso é ilustrado pelos 'textos sobre degeneração' acerca dos judeus, ciganos e pessoas deficientes (três grupos que os nazistas acreditavam ser 'entartet'). Além disso, o exemplo da degeneração das mulheres mostra como Nietzsche muitas vezes usou a palavra de modos retóricos e paródicos. Ele utilizou deliberadamente as crenças e preconceitos do seu tempo (nesse caso, as crenças sobre as mulheres), a fim de chamar a atenção para ameaças mais fundamentais, mas não observadas, à cultura e ao florescimento humano.

Palavras-chave: Entartung (degeneração) - Dekadenz (decadência) Nationalsozialismus (national-socialismo) - Rassismus (racismo) - Frauen (mulheres) - Kunst (arte)

\footnotetext{
* Tradução de Clademir Araldi.

** Professora da Radboud University Nijmegen, Holanda, e na Fontys University of Applied Sciences, Venlo, Holanda. Membro do Dutch Nietzsche Research Group. Este artigo é baseado principalmente em alguns dos materiais do verbete 'Entartung', que será publicado em breve, no segundo volume do Nietzsche-Wörterbuch (NWB), Berlim: Walter de Gruyter, 2011. E-mail: janskehermens@hotmail.com.
} 
Hermens, J.

Munique, 1937: a exposição "Entartete Kunst"

Em 1937, ocorreu em Munique uma das exposições mais notórias e mais visitadas da história da arte alemã. Ela foi chamada de "Entartete Kunst" ("Arte degenerada"), e mostrou as obras de arte de Max Beckmann, Oskar Kokoschka, Marc Chagall e Wassily Kandinsky, entre outros. Na palestra de abertura, o nacionalsocialista Adolf Ziegler comentou as obras de arte da seguinte forma: "Sie sehen um uns herum diese Ausgeburten des Wahnsinns, der Frechheit, des Nichtkönnertums und der Entartung. Uns allen verursacht das, was diese Schau bietet, Erschütterung und Ekel" ("Vocês vêem à nossa volta estes rebentos da loucura, da impertinência, da incapacidade e da degeneração. Causa em todos nós comoção e nojo tudo o que esta mostra oferece"). Seu discurso terminou com as palavras: "Deutsches Volk, komm und urteile selbst!" ("Povo alemão, venha e julgue você mesmo!") ${ }^{2}$.

As obras de arte foram deliberadamente apresentadas de forma caótica e desordenada. Algumas salas de exposição tinham temas específicos (como a suposta difamação das mulheres alemãs ou da religião cristã); outras, por exemplo, estavam repletas de obras de artistas judeus. Muitas pinturas estavam tortas e foram 'elucidadas' por textos pintados à mão, visando desvalorizar e tornar patológicos as obras de arte e os artistas. Às vezes, citações dos próprios artistas, isoladas de seu contexto original, foram usadas abusivamente com esse propósito. Por exemplo, o texto de dadaísta George Grosz: "Nehmen Sie Dada ernst - es lohnt sich!" ("Levem Dadá a sério - vale a pena!") foi pintado na Parede-Dadá. Em vários casos, as obras de arte foram postas lado a lado de fotografias de pessoas física e mentalmente deficientes, com 'deformações' faciais

1 ZIEGLER, A. "Zieglers Rede zur Eröffnung der Ausstellung 'Entartete Kunst"”. In: SCHUSTER, P.K. (org.), Nationalsozialismus und 'Entartete Kunst': die "Kunststad" München 1937. Munique: Prestel Verlag, 1987, p. 117.

2 Idem, p. 118.

88 | cadernos Nietzsche 31, 2012 
comparáveis às dos rostos representados nas pinturas. Em outros casos, obras de Klee e Kokoschka foram fixadas ao lado de imagens que pertenciam à "Coleção Prinzhorn"3.

O objetivo da exposição era mostrar que a 'Entartung' das obras expostas poderia remontar ao estado patológico de seus produtores. Deveria ficar claro ao público como essa arte moderna degenerada, "verjudete" ("judaizada") e bolchevista contrastava com o "gesundes Volksempfinden" (o senso comum saudável do povo alemão). De acordo com o partido nacional-socialista, a arte degenerada era 'infecciosa' e, como tal, uma ameaça para a saúde do povo alemão e para o Estado alemão. Adolf Hitler falou em seu discurso de abertura da Grossen Deutschen Kunstausstellung (uma exposição que foi planejada simultaneamente à exposição "Arte degenerada", e que foi concebida como a sua contraparte saudável) sobre "de[m] fortgesetzte[n] Versuch der Verwirrung des gesunden Menschenverstandes und Instinktes" ("a contínua tentativa de confundir o saudável senso comum com o instinto" $)^{4}$.

É por causa dessa herança nacional-socialista, que a palavra Entartung tornou-se um tabu na língua alemã ${ }^{5}$. Isso ficou claro, por exemplo, quando em 2007 o cardeal alemão Meissner falou sobre "die Entartung der Kultur" ("a degeneração da cultura"), por causa da separação entre arte e fé. Essa fala suscitou muitos protestos e discussões no público alemão ${ }^{6}$. A controvérsia foi suscitada não tanto pelo conteúdo, que o cardeal havia dito, mas por causa de sua escolha da palavra. No mesmo ano, Entartung foi eleita por uma comissão linguística acadêmica, coordenada pela Universidade

3 Prinzhorn foi um psiquiatra e historiador de arte, que reuniu as imagens feitas por seus pacientes esquizofrênicos, e publicou-as em 1922, num livro intitulado Bildnerei der Geisteskranken.

4 HITLER, A. " Hitlers Rede zur Eröffnung der 'Großen Deutschen Kunstaustellung”". In: SCHUSTER, P.-K. (org.). Nationalsozialismus und 'Entartete Kunst': die 'Kunststadt' München 1937. Munique: Prestel Verlag, 1987, p. 243.

5 Cf. PAUL. Deutsches Wörterbuch. Tübingen: Niemeyer, 2002.

6 Confira, por exemplo, o artigo no Frankfurter Allgemeine Zeitung, de 15 de julho de 2007. 
Hermens, J.

Goethe, em Frankfurt am Main, uma das três "Unworte des Jahres" ("palavras feias do ano").

Até que ponto o uso e abuso nazista de Entartung podem remontar a Nietzsche?

Houve muitos debates acerca de onde derivou esse vocabulário específico nacional-socialista de degeneração (não apenas a 'entartete Kunst' (arte degenerada), mas também as "entartete Mütter" ("mães degeneradas") ou as "entartete Rassen" ("raças degeneradas")). Alguns autores afirmam que foi claramente Nietzsche quem inspirou o uso dessa palavra; outros afirmam que ela derivou principalmente do psiquiatra judeu do século XIX, Max Nordau, que escreveu um livro muito influente sobre degeneração (intitulado "Entartung", publicado em 1892/93, em dois volumes); e outros ainda afirmam que ela foi inspirada em teorias racistas e nacionalistas do século XIX.

Foi Nietzsche quem inspirou a ideologia e o vocabulário nacional-socialista da degeneração? Aschheim escreve: "D'innombrables sources démontrent que la conception biopolitique de la dégénérescence et l'obsession nazie de ce concept étaient clairement inspirées par Nietzsche" ("Incontáveis fontes mostram que a concepção biopolítica de degeneração e a obsessão nazista por esse conceito foram claramente inspiradas por Nietzsche"). Outros afirmam que a maioria dos chefes da ideologia nazista, como o ideólogo do partido, Rosenberg, e também o próprio Hitler, pretenderam identificar-se com os pensamentos de Nietzsche, mas pouco leram seus textos e menos ainda entenderam o que ele estava dizendo ${ }^{8}$.

7 ASCHHEIM, S.E. "Max Nordau, Friedrich Nietzsche et "dégénérescence”. In: DELPHINE, B. (org.). Max Nordau. Paris: Les Éditions du Cerf, 1996, p. 144.

8 Confira, por exemplo, GERLACH, H.-M. "Politik (Faschismus, National-sozialismus,

90 | cadernos Nietzsche 31, 2012 
O desafio para o Nietzsche-Wörterbuch é tentar descobrir de que modos Nietzsche, efetivamente, usou as palavras "Entartung" e "Degeneration" (e ainda em outro verbete, "Dekadenz"). Uma das primeiras coisas que fica clara quando se analisa a palavra "Entartung", é que o uso de Nietzsche é muito mais diversificado do que, por exemplo, o dos nazistas. Quando usado pelos nazistas, "Entartung" tem uma conotação exclusivamente negativa, e é interpretado num sentido estreito, quase-biologista, evolutivo. Encontramos em Nietzsche conotações tanto "positivas" quanto "negativas": "Entartung" pode ser um sinal de declínio, mas também um estímulo para a vida; "Entartung" é utilizada de modos mais ou menos literais, mas também de modos metafóricos; "Entartung" é utilizada em um sentido "descritivo", mas também em contextos retóricos e paródicos. Muitas vezes, essa diversidade de usos é negligenciada por aqueles autores que querem defender, ou que Nietzsche foi um 'protofascista', ou por aqueles que querem provar o contrário. Os primeiros tendem a omitir as funções paródicas, irônicas e provocativas da palavra e os últimos muitas vezes ignoram o papel importante do corpo, da fisiologia e da biologia na obra de Nietzsche (especialmente desde a década de 1880), quando se trata de palavras problemáticas como "Entartung".

Tentaremos dar alguns exemplos. Nietzsche escreveu textos muito duros, que são citados por aqueles que querem deixar claro que ele foi uma fonte de inspiração para os nacional-socialistas. São exemplos de fragmentos que são citados vez por outra: „Absterbenmachen der Kläglichen Verbildeten Entarteten muß die Tendenz sein!“99 (Nachlass/FP 1880, 6[203], KSA 9.250s. ); ou „Eine neue Verantwortlichkeit schaffen, die des Arztes, für alle Fälle, wo das höchste Interesse des Lebens, des aufsteigenden

Sozialdemokratie, Marxismus)". In: OTTMANN, H. (ed.). Nietzsche Handbuch. Leben - Werk - Wirkung.Stuttgart: Verlag J.B. Metzler, 2000, p. 499ss.

9 “A tendência tem de ser a extinção dos miseráveis, deformados, degenerados!" (As traduções dos textos de Nietzsche, sem indicação de tradutor, são de minha responsabilidade. N. T.) 
Hermens, J.

Lebens, das rücksichtsloseste Nieder - und Beiseite-Drängen des entartenden Lebens verlangt - zum Beispiel für das Recht auf Zeugung, für das Recht, geboren zu werden, für das Recht, zu leben ... " " (GD/CI Incursões de um extemporâneo, 36, KSA 6.134); ou ,Jene neue Partei des Lebens, welche die grösste aller Aufgaben, die Höherzüchtung der Menschheit in die Hände nimmt, eingerechnet die schonungslose Vernichtung alles Entartenden und Parasitischen" ${ }^{\text {"Il }}$ (EH/EH, O nascimento da tragédia, 4, KSA 6.313). $\mathrm{Eu}$ penso que Taureck tem razão, quando diz que esses tipos de textos são frequentemente evitados por estudiosos de Nietzsche ${ }^{12}$.

Por outro lado, é importante ainda observar a unilateralidade de focalizar esses fragmentos, a fim de mostrar que Nietzsche foi realmente um tipo de precursor da ideologia nacional-socialista, como tentam fazer autores como Vacher ${ }^{13}$ ou Mittmann ${ }^{14}$, para citar apenas dois. A interpretação muito rasa seria que Nietzsche, com os textos citados acima, deu origem ao pensamento de que as pessoas consideradas inferiores deveriam ser extintas. O holocausto seria assim uma espécie de "pôr em prática" uma ideologia, da qual Nietzsche foi o precursor espiritual.

Quando se lê os textos de Nietzsche com cuidado, há vários pontos em que a acima mencionada interpretação 'rasa' de Nietzsche precisa ser nuançada. Poder-se-ia perguntar, por exemplo, se

10 "Criar uma nova responsabilidade, a do médico, para todos os casos em que o supremo interesse da vida, da vida ascendente, exige a mais implacável supressão e rejeição da vida que degenera - por exemplo, para os casos do direito à procriação, do direito de nascer, do direito de viver...” Trad. de Paulo César de Souza (PCS).

11 "Esse novo partido da vida, que toma em mãos a maior de todas as tarefas, o cultivo superior da humanidade, incluindo nisso o aniquilamento implacável de tudo o que é degenerado e parasitário". Trad. de Rubens Rodrigues Torres Filho (RRTF).

12 TAURECK, H. F. Nietzsche und der Faschismus. Ein Politikum. Leipzig: Reclam Verlag, 2000, p, 194s.

13 VACHER, L.-M. Le crépuscule d'une idole. Nietzsche et la pensée fasciste. Montréal: Liber, 2004.

14 MitTMAnN, Th. Vom 'Günstling' zum 'Urfeind' der Juden. Die antisemitische NietzscheRezeption in Deutschland bis zum Ende des Nationalsozialismus. Würzburg: Königshausen \& Neumann, 2006.

92 | cadernos Nietzsche 31, 2012 
Nietzsche identifica o Entartete com certos grupos de pessoas, como fizeram os nazistas, quando consideravam os judeus, ciganos ou pessoas deficientes como "entartet". Isso é o que faremos na próxima seção. Na última seção, veremos que é importante não só estudar o que Nietzsche disse sobre "Entartung" e "Entartete", mas também o que podem fazer essas palavras, o que elas provocaram no leitor; em suma, temos de estudar os aspectos performativos dos escritos de Nietzsche. Esse aspecto performativo será delineado por meio de uma leitura atenta de alguns fragmentos sobre um outro tema controverso, a saber, os fragmentos sobre mulheres e "Entartun".

"Entartung" e os deficientes, os judeus e os ciganos

O regime nazista identificou diferentes grupos de pessoas como "Untermenschen"15("seres sub-humanos') ou "Entartete". Entre eles, os mais conhecidos são os judeus, os "Roma" ("ciganos") e os deficientes. A ligação desses grupos específicos com "Entartung" não pode ser atribuída a Nietzsche. Vamos direcionar um olhar atento em alguns fragmentos específicos, em que deficientes, judeus e ciganos são referidos a "Entartung".

No aforismo 'Veredelung durch Entartung' (Enobrecimento por degeneração), Nietzsche critica o darwinismo. Ele escreve ali sobre os fracos e as pessoas deficientes:

selten ist eine Entartung, eine Verstümmelung, selbst ein Laster und überhaupt eine körperliche oder sittliche Einbusse ohne einen Vortheil auf einer anderen Seite. Der kränkere Mensch zum Beispiel wird vielleicht, inmitten eines kriegerischen und unruhigen Stammes, mehr Veranlassung haben, für sich zu sein und dadurch ruhiger und

15 É muito duvidosa a tentativa de remontar a Nietzsche o uso nazista da palavra 'Untermenschen'. Cf. o artigo sobre "Entartung" do NWB. 
weiser zu werden, der Einäugige wird ein stärkeres Auge haben, der Blinde wird tiefer in's Innere schauen und jedenfalls schärfer hören. Insofern scheint mir der berühmte Kampf um's Dasein nicht der einzige Gesichtspunct zu sein, aus dem das Fortschreiten oder Stärkerwerden eines Menschen, einer Rasse erklärt werden kann [...] gerade die schwächere Natur, als die zartere und freiere, macht alles fortschreiten überhaupt möglich ${ }^{16}$ (MA I/ HH 1 224, KSA 2.188).

Nesse aforismo, pessoas com deficiência são claramente avaliadas positivamente. Em primeiro lugar, sua deficiência em $\mathrm{um}$ domínio torna possível a excelência ou lhes dá força extra em um outro domínio (cegos terão ouvidos melhores, etc.) E, em segundo lugar, exatamente porque as pessoas com deficiência desviam-se do que é habitual, elas podem trazer revitalização e progresso para um povo como um todo.

Quando se trata de avaliação de Nietzsche dos judeus, há muitos lugares em que ele mostra que os judeus são exatamente o oposto de um ser "entarte". Autores como Aschheim ${ }^{17}$ e Mittmann 18 escreveram que muitos nacional-socialistas ficaram perturbados com as declarações pró-judeus e anti-antissemitas em Nietzsche, e com o fato de que as obras de Nietzsche foram apreciadas por muitos autores judeus. Nietzsche retrata o Israel antigo "do tempo

16 “[...] raramente uma degeneração, uma mutilação, mesmo um vício e em geral uma perda corporal ou ética deixam de ter uma vantagem por um outro lado. $\mathrm{O}$ homem mais doente, por exemplo, terá talvez, em meio a uma estirpe belicosa e intranquila, mais ocasião para ficar a sós e, por isso, tornar-se mais tranquilo mais sábio, o caolho terá um olho mais forte, o cego olhará mais profundamente para dentro e, em todo, caso, ouvirá mais agudamente. Nessa medida parece-me que a célebre luta pela existência não é o único ponto de vista a partir do qual pode ser explicado o progresso ou fortalecimento de um homem, de uma raça [...] precisamente a natureza mais fraca, sendo a mais delicada e fina, torna possível em geral todo progresso". (Trad. de RRTF))

17 Cf. ASCHHEIM, S. E. Max Nordau, Friedrich Nietzsche et „dégénérescence“. In: DELPHINE, B. (ed..), Max Nordau. Paris: Les Éditions du Cerf, 1996.

18 Cf. MITTMANN, Th. Vom 'Günstling' zum 'Urfeind' der Juden. Die antisemitische Nietzsche-Rezeption in Deutschland bis zum Ende des Nationalsozialismus. Würzburg: Königshausen \& Neumann, 2006.

94 | cadernos Nietzsche 31, 2012 
da monarquia" (AC/AC 25, KSA 6.193) como um povo forte e confiante em si. E mesmo os sacerdotes judeus posteriores são descritos como "o oposto de todos os decadentes" (AC/AC 24, KSA 6.192), se bem que não em um sentido positivo, enquanto eles promoveram a degeneração de outras pessoas. Em Nachlass/ FP 1887, 9[53], KSA 12.361, Nietzsche refere-se a Heine e a Offenbach, quando escreve que os judeus ,in der Sphäre der Kunst das Genie gestreift [haben] ${ }^{619}$ e por isso foram „eine rechte Erlösung von den gefühlsarmen und im Grunde entarteten Musikern der deutschen Romantik. “20

$\mathrm{O}$ terceiro grupo é formado pelos ciganos. Na ideologia nacional-socialista, assim como na literatura eugênica e criminal, ciganos, prostitutas e criminosos eram frequentemente compreendidos como um e o mesmo grupo de 'associais', como uma subclasse inferior e degenerada ${ }^{21}$. Mesmo que possamos encontrar observações similares de criminosos (etc), especialmente nos fragmentos póstumos de Nietzsche, de 1888, sobretudo em trechos do psiquiatra francês Charles Féré, esses fragmentos estão longe de serem representativos. Isso pode ser observado, por exemplo, quando lemos o trecho do Nachlass/FP 1884, 25 [19], KSA 11.17, em que Nietzsche cita quase literalmente Francis Galton. Galton descreve como originalmente os "Verbrecher" ("criminosos") foram muitas vezes pessoas muito fortes, que adoeceram por causa da má influência da sociedade moderna. Segundo ele, "o caráter de tipo cigano da raça não era adequado para o sucesso em um país civilizado" ${ }^{22}$. Nietzsche traduz (ou: interpreta), esses ancestrais

19 "tocaram de leve o gênio, na esfera da arte".

20 "uma autêntica redenção dos músicos, pobres de sentimento e no fundo degenerados, do Romantismo alemão".

21 Para uma análise mais detalhada da história 'esquecida' da perseguição nazista aos ciganos, uma obra de referência é: LEWY, G. The Nazi Persecution of the Gipsies. Oxford: Oxford University Press, 2000.

22 GALTON, F. Inquiries into Human Faculty and its Development. Londres: Macmillan, 1883. Citado em: HAASE, M. L. Friedrich Nietzsche liest Francis Galton. In: Nietzsche Studien, 18, 1989, p. 639. 
Hermens, J.

'de tipo cigano' dos criminosos em seu Nachlass como "HalbWilde (brave gesunde Jäger Fischer [...])"233 e escreve sobre eles numa carta a Strindberg: "Der hereditäre Verbrecher décadent, selbst Idiot - kein Zweifel! Aber die Geschichte der Verbrecher Familien, für die der Engländer Galton (,the hereditary genius“) das größte Material gesammelt hat, führt immer auf einen zu starken Menschen für ein gewisses sociales niveau zurück" (A Strindberg, 08 de dezembro de 1888, KSB 8.508) ("O criminoso hereditário décadent, idiota mesmo - não há dúvida! No entanto, a história das famílias de criminosos, sobre as quais o inglês Galton ("o gênio hereditário") juntou o material mais amplo, sempre remonta a um ser humano, que é forte demais para um nível social específico"). A expressão 'Halb-Wilde' ('semibárbaros') tem claramente uma conotação positiva ${ }^{24}$. Nietzsche fala sobre pessoas (anteriormente) fortes e saudáveis, com instintos e impulsos poderosos. Quando ele afirma que essas pessoas são 'entartet', a conotação negativa da palavra não é claramente dirigida a essas pessoas (anteriormente) fortes, nem ao que Galton chamou de "caráter de tipo cigano da raça" ("gipsy-like character of the race"), mas à sociedade contemporânea de Nietzsche e sua moralidade cristã. O tipo 'rapinante' ("raubthierhafte") de pessoa precisa interiorizar seus impulsos ou expressá-los de um modo destrutivo, por exemplo, criminoso, por causa das tentativas do cristianismo de agrilhoar e de "civilizar" todos os que são fortes ou "anormais".

Entretanto, se "Entartung" não significa para Nietzsche a degeneração de determinados grupos de pessoas, como os judeus, os ciganos e as pessoas deficientes, a quem ela se aplica? A resposta é tão simples quanto verdadeira: "Entartung" pode ser aplicada, e é aplicada por Nietzsche, a quase tudo. Ela é aplicada a todos os tipos de pessoas. É aplicada a cristãos, às massas, aos artistas, aos

23 "Semibárbaros (bravos, saudáveis caçadores e pescadores [...])".

24 Cf. também JGB/BM 197, KSA 5.117; GD/CI 9 45, KSA 6.146s.; Nachlass/FP 1888, 14 [133], KSA 13.317.

96 | cadernos Nietzsche 31, 2012 
escritores e filósofos, às mulheres, aos alemães e aos criminosos, para citar alguns dos mais proeminentes. E, certamente, podemos acrescentar os acima mencionados judeus, ciganos e pessoas deficientes, embora eles figurem com menos proeminência. Mais importante, contudo, é que Nietzsche tenta mostrar que 'degeneração' é um processo que a tudo permeia, que não se limita a certos grupos de pessoas, como certas 'raças'. Em um fragmento póstumo, que trata das características do cristianismo, Nietzsche afirma explicitamente: „die christliche Bewegung ist eine DegenerescenzBewegung aus Abfalls- und Ausschuß-Elementen aller Art: sie drückt nicht den Niedergang einer Rasse aus, sie ist von Anfang an eine Aggregat- Bildung aus sich zusammendrängenden und sich suchenden Krankheits-Gebilden... Sie ist deshalb nicht national, nicht rassebedingt: sie wendet sich an die Enterbten von Überall ${ }^{625}$ (Nachlass/FP 1888, 14[91], KSA 13.267s.). Além disso, "Entartung" não se aplica apenas a seres humanos, mas também aos órgãos e organismos, às sociedades e culturas, à música e à literatura.

Haja vista que "Entartung" pode ser aplicada a quase tudo, a questão "o que Nietzsche, de fato, quer dizer com "Entartung"?" vem a ser ainda mais importante. O que acontece quando algo degenera? De novo, encontramos várias respostas. 'Entartung' é, dentre outros sentidos, descrita como um desvio, de algo ou de alguém, de sua identidade (corporal) ou de suas origens. Com frequência, ocorre uma fragmentação ou uma decomposição de uma totalidade (quase) orgânica e, assim, uma perda de ligação ou de tensão entre as partes constitutivas. Esse processo caracterizase por uma perda de força agonal, por uma privação de 'InstinktSicherheit' ("certeza do instinto') ou por uma "Disgregation des

25 "O movimento cristão é um movimento de degenerescência, a partir dos detritos e dos refugos de toda espécie: ele não expressa a decadência de uma raça, ele é desde o início um agregado de formações doentias que se concentram e buscam a si mesmas... Por isso, ele não é nacional, não é condicionado pela raça: ele se volta aos deserdados de tudo". 
Hermens, J.

Willens" ("desagregação da vontade"), por uma falta de medida ou temperança, pela incapacidade de discriminar e selecionar, e por uma irritabilidade extrema e um desejo de estímulos sensuais.

Mesmo que não possa entrar em detalhes acerca das caracterizações de "Entartung", por mim mencionadas anteriormente, é importante notar que quase todas elas referem, direta ou indiretamente, à teoria nietzschiana da vontade de potência. "EntArtung" parece ser um desvio ou uma diminuição da "Art" de alguém, e não (apenas) como um alemão, como um cristão, como um ser humano ou como uma nação, mas de sua "Art" ou "natureza" mais fundamental, que é: vontade de potência. "Entartung" é descrita como um enfraquecimento de um organismo, de tal modo que ele perde a sua "plastische Kraft" ("força plástica"), a sua capacidade para superar forças contrárias e para crescer através de sua superação. Ser "entartet" significa não possuir mais o gosto discriminatório, que nos diz o que é benéfico e o que é prejudicial ao nosso organismo. Falta-nos a capacidade de selecionar, não sabemos o que incorporar e o que expelir. Tudo o que nos atinge, nos machucará, nos ferirá. E quando estamos feridos, falta-nos a capacidade para regenerar a nós mesmos, a nossa compleição se enfraquecerá, irá deteriorar-se a cada ataque que tivermos de suportar.

\section{A "Anähnlichung" dos sexos e a degeneração das mulheres}

Uma das condições necessárias para a vontade de potência florescer ocorre em uma pluralidade de forças e de forças antagônicas. Um organismo só pode crescer quando há forças antagônicas (outras vontades de potência), sobre as quais ele pode exercer a sua potência. Quando as oposições desaparecem ou quando as coisas que são diferentes aproximam-se umas das outras, a relação de tensão estabelecida entre elas se afrouxa, e a diferença ameaça convergir em mesmice. Nietzsche descreve esse mecanismo, ao empregar o termo "Anähnlichung" ("assimilação" 
ou "aproximação"). Ele o aplica, entre outras, na sua descrição da degeneração das mulheres modernas.

À primeira vista, a maioria dos textos de Nietzsche sobre as mulheres e, certamente, aqueles sobre a degeneração das mulheres, estão em sintonia plena com a moralidade (sexual) do século XIX. De acordo com Moore, muitas das imagens burguesas contemporâneas das mulheres são refletidas nas obras de Nietzsche. Nessa visão de mundo, as mulheres são associadas à "doença e fraqueza", e marcadas por características como "nutrição, moralidade intuitiva, domesticidade, passividade e afeição" ${ }^{\text {26 }}$. Moore está parcialmente certo em relação a essa afirmação. Quando se trata da 'Entartung' das mulheres, nós encontramos várias descrições quase estereotipadas. Por exemplo, Nietzsche fala sobre a Entartung das mulheres que não querem ter filhos (Nachlass/FP 1885, 34[153], KSA 11.472), ou ele refere a histeria das mulheres wagnerianas à sua incapacidade de ter filhos (Nachlass/FP 1888, 15 [99], KSA 13.465).

Entretanto, quando observamos mais atentamente alguns textos sobre a degeneração das mulheres, podemos descobrir que eles de fato não são "convencionais" em absoluto. Em vários casos, há algo de errado com a afirmação de Moore, de que Nietzsche usa o debate contemporâneo sobre a degeneração, para fortalecer suas próprias "visões profundamente conservadoras e totalmente convencionais sobre as mulheres e a sexualidade"27. Há vários lugares em que Nietzsche desafia a imagem burguesa convencional das mulheres como seres fracos e frágeis, ou em que ele usa (ou melhor, "explora" ou "instrumentaliza") essas concepções, a fim de chamar a atenção para o que ele percebe ser o problema mais fundamental. Ele faz isso, usando as percepções familiares (ou preconceitos) sobre as mulheres, tomando, desse modo, seus leitores pela mão, seduzindo-os a realizar conjuntamente sua linha

26 MOORE, G. Nietzsche, Biology, and Metaphor. Cambridge: Cambridge University Press, 2002, p. 129.

27 MOORE, op. cit., p. 194. 
de pensamento. Em um nível mais profundo, ou às vezes por causa de uma inflexão no texto, é provocado ou trazido à luz um outro tema, muito menos compartilhado, porém mais importante, em concordância com Nietzsche.

Às vezes, Nietzsche usa a fraqueza percebida das mulheres para chamar a atenção de seus leitores para um outro fenômeno cultural subjacente, qual seja, da dissolução das diferenças e da fusão de opostos. Quando Nietzsche fala sobre a feminização dos homens ou sobre a masculinização das mulheres, deveríamos ler isso, entre outros modos, como um sintoma de um processo subjacente, a saber, o processo de "Nivellirung" (nivelamento) das diferenças entre as pessoas, que ele vê simbolizado em processos como democratização e "Verpöbelung" (vulgarização) da cultura. Ele assim procede, por exemplo, quando fala da degeneração dos homens ou dos 'valores masculinos', por causa da feminização da nossa cultura ${ }^{28}$. Aqui ele apanha e faz uso de um tema amplamente discutido na Alemanha do século XIX, (qual seja, a "feminização" ou "enfraquecimento" de muitos domínios da cultura ${ }^{29}$; e usa-o retoricamente, a fim de mostrar um problema mais fundamental em nossa cultura contemporânea. Além disso, quando Nietzsche alerta para o enfraquecimento e a feminização, e defende a necessidade de uma cultura mais "viril", deve-se sempre ter em mente que ele procede especificamente de seu ponto de vista masculino. É uma de suas 'armas' na luta entre os valores e entre os sexos; é um meio para aguçar a diferenças e, assim, intensificar a luta.

Lancemos um olhar mais preciso ao efeito degenerativo da "masculinização das mulheres" ("Vermännlichung der Weiber" (Nachlass/FP 1884, 26[36], KSA 11.245)). Nietzsche afirma

$28 \mathrm{Na}$ obra de Nietzsche, o contraste entre épocas mais viris e fortes (como o Renascimento) e épocas mais fracas (como o século XVIII) aparece muitas vezes (cf., por exemplo, Nachlass/FP 1887, 9[178], 12.440). Já a feminização dos romanos foi vista como um sinal de degeneração e foi vinculada por vários autores à influência do cristianismo (cf. GILMAN, R. Decadence.

The Strange Life of an Epithet. Nova York: Farrar, Straus and Giroux, 1975, p. 48s.).

29 Cf. por exemplo MA II/HH II, Prefácio, 3, KSA 2.373. 
que, por causa da masculinização das mulheres, não apenas as diferenças entre homens e mulheres são niveladas, mas as mulheres também perdem algo de sua identidade feminina e, desse modo, de seu poder feminino específico. A descrição desse poder feminino específico é o oposto das características tipicamente femininas, acima mencionadas, promovidas pela percepção burguesa das mulheres. Em JGB/BM, Nietzsche escreve que é a masculinização das mulheres que leva as mulheres a "[d]ie Witterung dafür verlieren, auf welchem Boden man am sichersten zum Siege kommt; [dass sie] die Übung in [ihrer] eigentlichen Waffenkunst vernachlässigen“30 (JGB/BM 239, KSA 5.176). De modo voluntário, as mulheres abandonam exatamente aquelas características que constituem seu poder feminino:

Das, was am Weibe Respekt und oft genug Furcht einflösst, ist seine Natur, die "natürlicher" ist als die des Mannes, seine ächte raubthierhafte listige Geschmeidigkeit, seine Tigerkralle unter dem Handschuh, seine Naivität im Egoismus, seine Unerziehbarkeit und innerliche Wildheit, das Unfassliche, Weite, Schweifende seiner Begierden und Tugenden... ${ }^{31}$ (JGB/BM 239, KSA 5.178).

Segundo Nietzsche, as mulheres são caracterizadas por um tipo de selvageria natural livre: "Güte am Weibe ist schon eine Form der Entartung ..." ${ }^{32}$ (EH/EH Por que escrevo livros tão bons, 5, KSA 6.306). É altamente inadequado, de acordo com Nietzsche, sentir pena das mulheres ou tentar "civilizá-las". A tentativa de "civilizar' uma pessoa mais "selvagem" ou "desajustada" quase

30 "Perder a intuição do terreno onde a vitória é mais segura; descuidar o exercício de sua verdadeira arma". Trad. de PCS.

31 "O que na mulher inspira respeito e com frequência temor é sua natureza, que é 'mais natural' que a do homem, sua autêntica astuciosa agilidade ferina, sua garra de tigre por baixo da luva, sua inocência no egoísmo, sua ineducabilidade e selvageria interior, o caráter inapreensível, vasto, errante de seus desejos e virtudes..." Trad. de PCS.

32 "Bondade na mulher já é uma forma de degeneração...". 
sempre acarreta um enfraquecimento e, assim, uma degeneração dessa pessoa (confira, por exemplo, o exemplo dos ciganos, na seção anterior). Nietzsche abomina, portanto, aqueles „Esel [.] Männlichen Geschlechts“, que tentam rebaixar (herunterbringen) as mulheres à ,"allgemeinen Bildung", wohl gar zum Zeitungslesen und Politisiren“333 (JGB/BM 239, KSA 5.177).

Édevidoaofato de que a emancipação(nas palavras de Nietzsche, 'masculinização') das mulheres leva a um enfraquecimento e a uma desnaturalização dos pontos fortes femininos específicos, que Nietzsche acredita ser já a escolha da emancipação um sintoma da "Entartung" das mulheres contemporâneas. De acordo com ele, uma das principais características dos degenerados é que eles escolhem os meios que os tornam ainda mais doentes. "Ich sehe darin [in der Emanzipation] eine Entartung im Instinkte der jetzigen Weiber: sie müßten wissen, dass sie ihre Macht zu Grunde richten, auf diesem Wege. -, ${ }^{34}$ (Nachlass/FP 1884, 26 [361], KSA 11.246). Tanto a 'civilização' das mulheres quanto a sua "masculinização", têm um efeito degenerativo nas mulheres $e$ na sociedade. Ao serem "civilizadas", as mulheres são rebaixadas ao estado doentio de seus contemporâneos do sexo masculino, e ao "masculinizaremse", elas perdem o seu poder feminino característico. Tanto a despotenciação das mulheres quanto seus movimentos em direção a uma convergência com o homem, diminuem a possibilidade de relacionamentos fortes, aguerridos e cheios de tensão entre os sexos, e assim contribuem para a deterioração, ou, nas palavras de Nietzsche, para a degeneração da cultura.

33 “formação geral', e mesmo à leitura de jornais e à politização".

34 "Eu vejo nisso [na emancipação] uma degeneração nos instintos das mulheres de hoje: elas deveriam saber, que elas desse modo arruínam seu poder". 


\section{Conclusão}

Se olharmos para a avaliação positiva de Nietzsche dos deficientes, dos ciganos e dos judeus, e se olharmos também para a avaliação 'negativa' da aproximação entre homens e mulheres, o tema da ameaça de afrouxamento das diferenças e do desaparecimento da luta parece ser central. Por exemplo, os deficientes foram descritos como aqueles que poderiam revitalizar uma cultura que se tornou preguiçosa e fatigada, exatamente porque eles se desviaram da média. Eles poderiam funcionar como uma força antagônica, que provoca o organismo societário e faz com que ele tenha que despertar e defender-se. E, no sentido inverso, uma das principais razões para Nietzsche voltar-se contra a "Vermännlichung der Weiber" (Nachlass/FP 1884, 26 [361], 11.245), como vimos, teve a ver exatamente com os efeitos perigosos da equalização dos poderes conflitantes. As diferenças não deveriam ser mitigadas, segundo Nietzsche, mas deveriam ser estimuladas e intensificadas. Nietzsche adverte para as consequências da fusão de virtudes opostas: „Das ist so wenig, wünschbar, als die Annäherung und Aussöhnung der Geschlechter $^{6 \otimes}$ (Nachlass/FP 1887, 10 [59], 12.492).

Nessa perspectiva, tornam-se ainda mais duvidosas as referências frequentes dos nazistas a Nietzsche, como a fonte para a sua ideologia biopolítica unidimensional. Os artistas que foram mostrados na exposição sobre arte degenerada, de 1937, foram exatamente os vanguardistas na arte, que fizeram a diferença, que tentaram provocar as opiniões dominantes. Seria interessante saber, se Nietzsche ainda estivesse vivo, se ele teria percebido exatamente esses artistas como a avant garde da mudança cultural que ele estava esperando ${ }^{35}$.

Foram exatamente essas pessoas que produziram algo extraordinário, como é o caso de muitos dadaístas ou expressionistas,

35 "Isso é tão pouco 'desejável', quanto a aproximação e conciliação dos sexos". 
os quais estavam sendo troçados pelas massas e por aqueles que detinham poder político. Num póstumo de Nietzsche, de 1878, podemos ler o seguinte fragmento, que descreve exatamente esse mecanismo: "Wer etwas vollbringt, das über den Gesichts- und Gefühlskreis der Bekannten hinausliegt: — Neid und Hass als Mitleid - Partei betrachtet das Werk als Entartung Erkrankung Verführung. Lange Gesichter ${ }^{636}$ (Nachlass/FP, 30[40], KSA 8.528). Nietzsche diz mais uma vez que é perigoso identificar alguém ou algo como 'degenerado' (e, a propósito, é exatamente esse perigo que torna o uso desta palavra tão atrativo para Nietzsche!). Esses fenômenos culturais, que são um sinal ou uma causa da degeneração, não são com frequência reconhecidos como tais, enquanto, de modo inverso, as pessoas que incorporam a forma mais elevada de saúde são muitas vezes "patologizados" pelos "normais". Em O caso Wagner, Nietzsche fala sobre o "caráter de Proteu da degenerescência' (WA/CW 5, KSA 6.22s.). Proteu, como é bem conhecido, era o deus grego que sempre assumia uma forma diferente, quando alguém tentava obter informações dele. Além disso, conforme Nietzsche, a linha demarcatória entre loucura e genialidade é frequentemente muito tênue ${ }^{37}$. Para concluir, um trecho do prefácio ao Nascimento da Tragédia:

Wie? Ist nicht Wahnsinn vielleicht nothwendig das Symptom der Entartung, des Niedergangs, der überspäten Cultur? Giebt es vielleicht - eine Frage für Irrenärzte - Neurosen der Gesundheit?38 (GT/NT, Tentativa de autocrítica, 4. KSA 1.16).

36 Confira, entre outros textos, JGB/BM 203, KSA 5.127.

37 "Quem produz algo, que está além do campo de visão e de sentimentos dos conhecidos: inveja e ódio como compaixão - O partido considera a obra como degeneração, adoecimento, sedução. Desilusão".

38 No artigo "Entartung", do NWB, a noção de parentesco entre loucura e genialidade, amplamente discutida no século XIX, será discutida de forma mais elaborada. Confira também o artigo sobre o 'gênio' (Genie) do NWB. 


\begin{abstract}
Nietzsche is often believed to be one of the sources of inspiration of the Nazi use of the word 'Entartung', which is notorious amongst others because of the Nazi concept of 'Entartete Kunst'. In this essay it is defended that Nietzsche's use of the word was quite diverse and ambiguous, and does not fit to Nazi use. First of all Nietzsche did not limit his use of 'degeneration' to the physiological domain or to specific groups of people. This is illustrated by 'degeneration- texts' on Jews, Roma and handicapped people (three groups that were believed to be 'entartet' by the Nazi's). Moreover, by the example of the degeneration of women it is shown, how Nietzsche used the word often in rhetorical and parodical ways. He deliberately used the beliefs and prejudices of his time (in this case, beliefs on women) in order to put attention to more fundamental, but unobserved, threats to culture and human flourishing. Keywords: Entartung (degeneration) - Dekadenz (decadence) Nationalsozialismus (National Socialism) - Rassismus (racism) - Frauen (women) - Kunst (art)
\end{abstract}

\title{
referências bibliográficas
}

ASCHHEIM, S.E. Max Nordau, Friedrich Nietzsche et „dégénérescence“. In: DELPHINE, B. (org.), Max Nordau. Paris: Les Éditions du Cerf, 1996.

GALTON, F. Inquiries into Human Faculty and its Development. Londres: Macmillan, 1883.

GERLACH, H.-M. Politik (Faschismus, National-sozialismus, Sozialdemokratie, Marxismus). In: OTTMANN, H. (ed.). Nietzsche Handbuch. Leben - Werk Wirkung. Stuttgart: Verlag J. B. Metzler, 2000.

GILMAN, R. Decadence. The Strange Life of an Epithet. Nova York: Farrar, Straus and Giroux, 1975.

HAASE, M. L. Friedrich Nietzsche liest Francis Galton. In: Nietzsche Studien, 18, 1989.

HITLER, A. Hitlers Rede zur Eröffnung der 'Großen Deutschen Kunstaustellung'. In: SCHUSTER, P.-K. (ed..)Nationalsozialismus und 'Entartete Kunst': die 'Kunststadt' München 1937. Munique: Prestel Verlag, 1987.

LEWY, G. The Nazi Persecution of the Gipsies. Oxford: Oxford University Press, 2000.

MITTMANN, Th. Vom 'Günstling' zum 'Urfeind' der Juden. Die antisemitische Nietzsche-

Rezeption in Deutschland bis zum Ende des Nationalsozialismus. Würzburg: Königshausen \& Neumann, 2006.

MOORE, G. Nietzsche, Biology, and Metaphor. Cambridge: Cambridge University Press, 2002. 
Hermens, J.

PAUL Deutsches Wörterbuch. Tübingen: Niemeyer, 2002.

PRINZHORN, H. Bildnerei der Geisteskranken. Berlin: Verlag Julius Springer, 1922.

TAURECK, H.F. Nietzsche und der Faschismus. Ein Politikum. Leipzig: Reclam Verlag, 2000.

VACHER, L.-M. Le crépuscule d'une idole. Nietzsche et la pensée fasciste. Montréal: Liber, 2004.

ZIEGLER, A. ,Zieglers Rede zur Eröffnung der Ausstellung 'Entartete Kunst”, in: SCHUSTER, P.-K. (Hrsg.), Nationalsozialismus und 'Entartete Kunst': die 'Kunststadt' München 1937. Munique: Prestel Verlag, 1987.

Artigo recebido em 17/05/2011.

Artigo aceito para publicação em 10/08/2011.

106 | cadernos Nietzsche 31, 2012 